\title{
Multi-step icing calculations using a 3D multi-block structured mesh generation procedure
}

\author{
K. Hasanzadeh ${ }^{1}$, D. Pena ${ }^{2}$, Y. Hoarau ${ }^{3}$, E. Laurendeau ${ }^{4}$ \\ 1,4, Département de Génie Mécanique, École Polytechnique, C.P. 6079, Centre-Ville, \\ Montréal (QC), H3C 3A7, Canada \\ 2,3, Université de Strasbourg, 2 Rue Boussingault, F - 67000 STRASBOURG
}

An Extended Abstract to

SAE 2015 International Conference on Icing of Aircraft, Engines, and Structures

June 22-25, 2015

Prague, Czech Republic

The paper will present the framework of fully automated two/three dimensional ice accretion simulation package NSMB3D-ICE, with emphasis on the remeshing step. The NSMB3D-ICE Navier-Stokes code, coupled to an Eulerian droplet module and iterative Messinger thermodynamic model, can perform multi time-steps ice accretion simulations via an automated multi-block elliptic/parabolic grid generation code (NSGRID3D). Attention is paid to the efficiency and robustness of the numerical procedure especially for complex 3D glaze ice simulation. The new automated multi time-step icing code NSMB3D-ICE/NSGRID3D is validated and verified using several icing case studies such as the GLC305-3D rime and glaze ice cases.

The Navier-Stokes flow solver NSMB3D is a finite volume three-dimensional multiblock Euler/Navier-Stokes flow solver developed by J. Vos et al. [1-3]. The code is being developed by a group of researchers across Europe and now in Canada, and benefits from state-of-the-art advances in computational techniques: low Mach number preconditioning, Full Approximate Storage Multigrid, dual time stepping marching schemes for steady and unsteady flows simulations, Arbitrary Eulerian-Lagrangian formulation suitable for aero-elastic calculations, and parallel implementation. Available turbulence models include the widely used Spalart-Allmaras and k- $\omega-$ SST equations with/without roughness. The chimera approach is also implemented [4,5]. Validations have been presented at the AIAA validation workshop series, namely drag predictions [6], high-lift [7] and aero-elastic [8] and in a number of European framework program reports [9]. The NSMB solver is also used within the multi-time steps framework of icing Simulation CANICE2D-NS [10-11]. The new development in NSMB3D made the code capable of ice accretion simulations, albeit with only a single time step approach. The

\footnotetext{
${ }^{1}$ PhD Student, kazem.hasanzadeh@polymtl.ca

${ }^{2} \mathrm{PhD}$ Student, dorian.pena@polymtl.ca

${ }^{3}$ Associates Professor, hoarau@unistra.fr

${ }^{4}$ Associates Professor, eric.laurendeau@polymtl.ca
} 
NSMB3D-ICE icing simulation includes 4 main steps: RANS flow simulation, Eulerian droplet computation, iterative Messinger thermodynamic module solved with a NewtonKrylov solver and ice growth computations [12]. To perform multi-time steps 3D ice accretion simulation especially for complex glaze ice formation, NSMB3D-ICE has now been coupled with the elliptic/parabolic multi-block grid generation code NSGRID3D.

NSGRID-2D/3D is a two and three multi-block multi-grid elliptic/parabolic grid generation code developed at the research laboratory of Professor Eric Laurendeau at École Polytechnique Montreal. The code is capable of grid generation and smoothing for complex domains such as 2D/3D experimental glaze ice shapes. It includes a choice of control functions ensuring spacing, curvature and orthogonality requirements, including a novel blended approach which mixes the use of Sorenson and Spekreijse functions within a parabolic marching method. A novel automated curvature control algorithm is also implemented to control the arclength grid spacing, so that high curvature regions around ice horns are appropriately captured while avoiding the grid shock problem. The mesh generation solver includes several solution algorithms (Point-Jacobi, Gauss-Seidel, ADI, Line SOR) within the context of an efficient full multigrid operator. NSGRID has been validated trough different complex experimental ice simulation [13-15]. The code also has been used by the framework of multi-time steps icing CANICE2D-NS at École Polytechique Montreal and Bombardier Aerospace, as well as the Eulerian multi-time steps icing simulation code at Ecole Polytechnique Montreal, and many other grid generation applications for complex geometries such as iced airfoils and high lift systems [16- 19]. Note that only 2D cases have been published so far (Figure 1), with this paper providing the first $3 \mathrm{D}$ extension of the developed algorithms. In particular, the $2 \mathrm{D}$ and 3D results show the quality of the resulting mesh generation algorithm, with orthogonality between $0.85-1$ and near-constant $y+$ near-wall values of the first cell height.

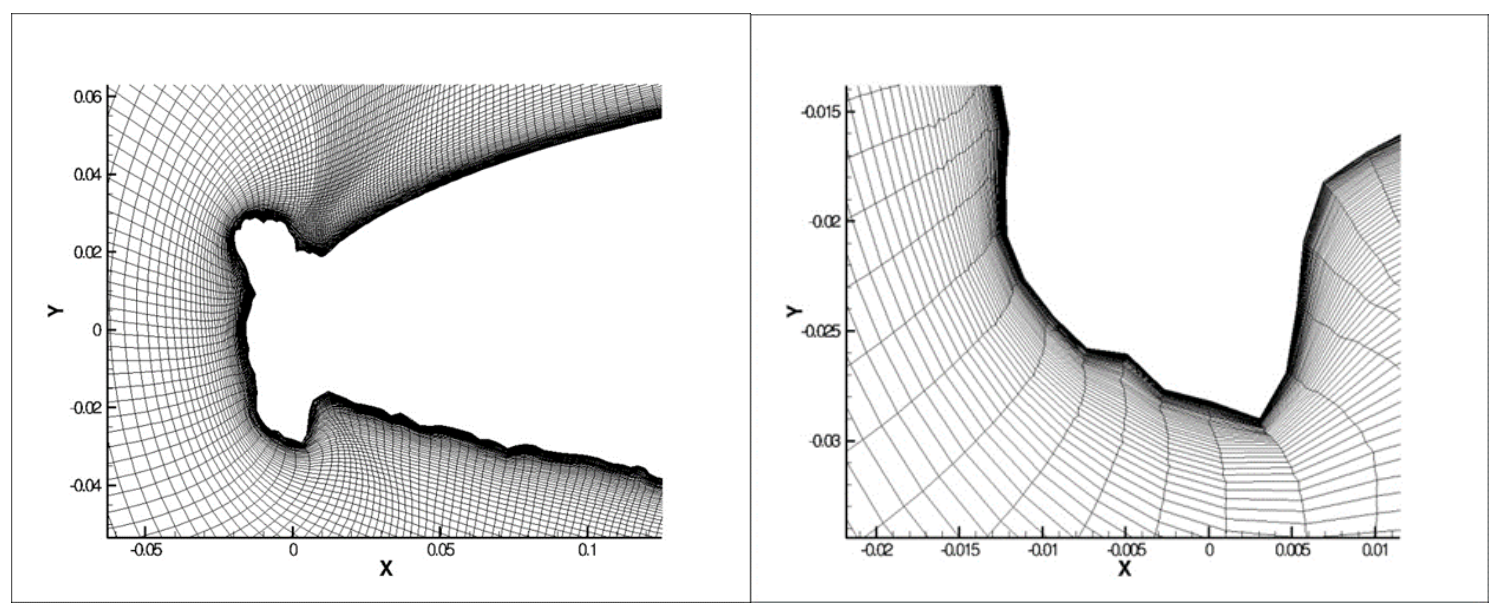

Fig. 1 left: 2D structured grid generated with NSGRID; right: lower horn detail 
Below, we present the results of Rime ice multi-time steps simulation on the GLC305-3D wing. The objective is to validate the 3D icing simulation, 3D grid generation and the multi-time steps framework of the coupled code. The complementary results will include the simulation of complex glaze ice formation on GLC305-3D using the multi-time steps framework.

\section{GLC305-3D run Ice3 or IRT-SC5 Rime ice}

The test conditions are listed in Table 1 [20]. The clean wing 3D structured grid generated includes around 3,000,000 nodes and wall spacing of $210^{-6}$ chord on the first layer on each plane. The selected surface roughness values $\mathrm{k}_{\mathrm{s}}$, are held constant during each calculations. Three time steps has been decided for the icing computation and after each time steps and ice accumulation, the surface and domain grid are re-generated.

Table 1 GLC305 run Ice3 or IRT-SC5 test

conditions

\begin{tabular}{lc}
\hline \hline Angle of Attack & $6 \mathrm{deg}$. \\
Flight Speed & $201 \mathrm{mph}$ \\
Static Temperature & $11.7^{\circ} \mathrm{F}$ \\
LWC & $0.51 \mathrm{~g} / \mathrm{m}^{3}$ \\
MVD & $14.5 \mu \mathrm{m}$ \\
Icing Duration & $5 \mathrm{~min}$ \\
Icing Time-Steps & 3 times 100 -sec. steps \\
\hline \hline
\end{tabular}

The computational surface meshes generated for the clean and $3^{\text {th }}$ time-step accumulated ice is shown in Figure 2. Figure 3 shows the generated and smoothed grid for the final ice accumulated surface. Figures 4-5 shows that the quality of the mesh has been retained throughout the procedure, with orthogonality/stretching of grid close to the wall obtained using the elliptic/parabolic methods of NSGRID3D.

In the final paper, comparisons with more icing test cases, especially 3D complex glaze ice cases for GLC305-3D, will be made. The grid solution and quality metrics will be examined on complex glaze ice formation. The effect of the multi-grid approach and parallel MPI processing of the mesh generation step will be examined, showing the significant reduction in computation times via this mesh regeneration procedure. 


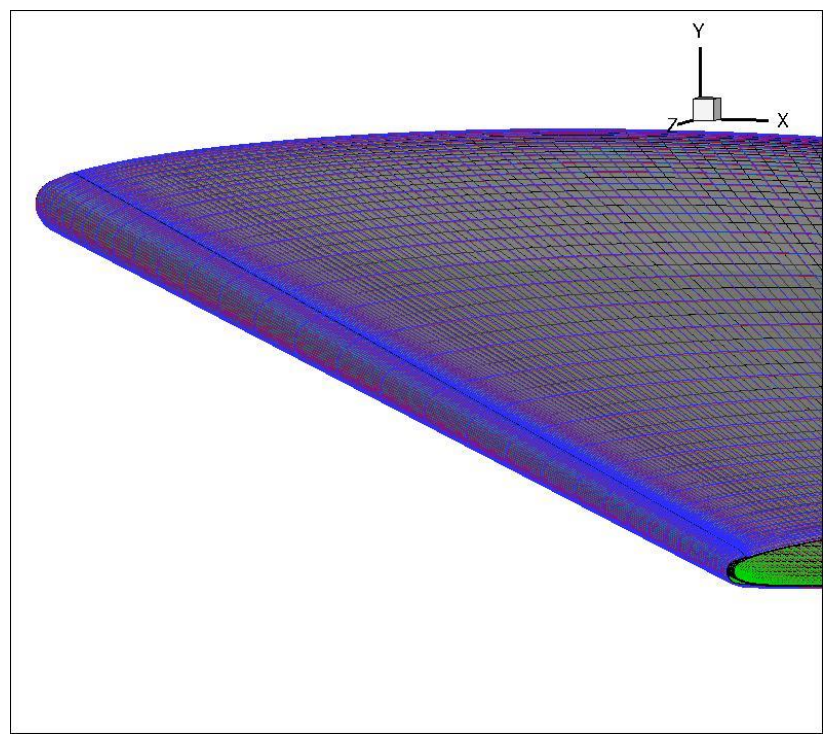

Fig. 2 Surface mesh generated form clean to the final accumulated ice shape (NSMB3DICE/NSGRID3D).

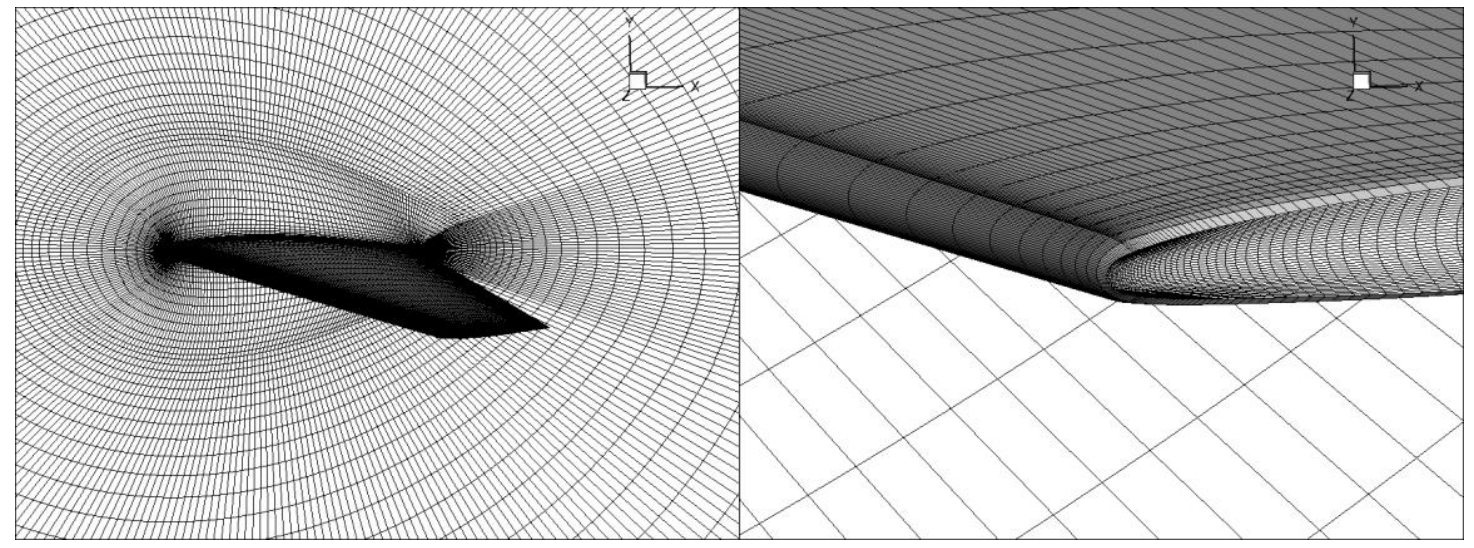

Fig. 3 Grid generated and smoothed for the final ice accumulated surface. 


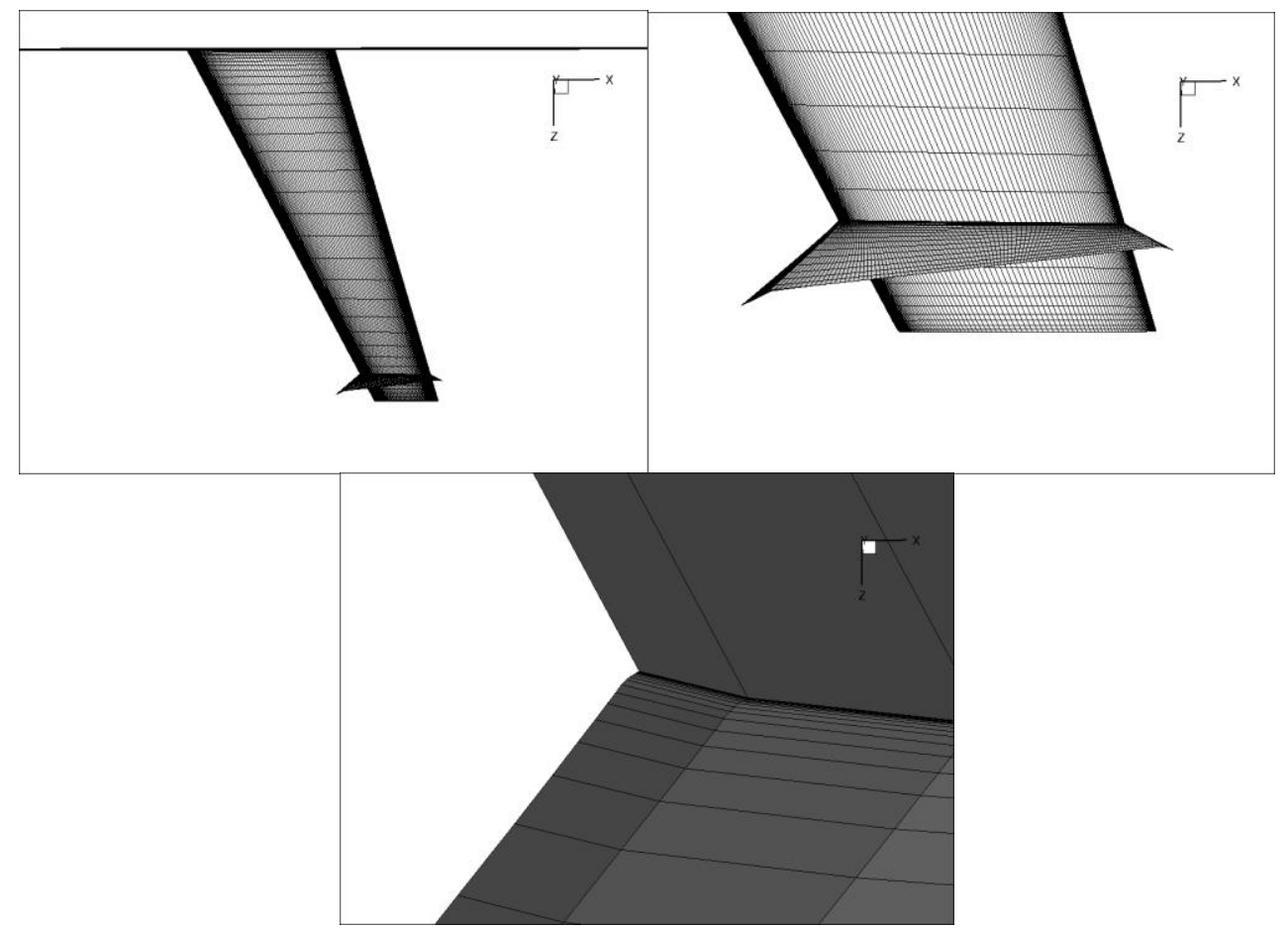

Fig. 4 Orthogonality/stretching check close to wall of the generated grid for iced surface (NSGRID3D).

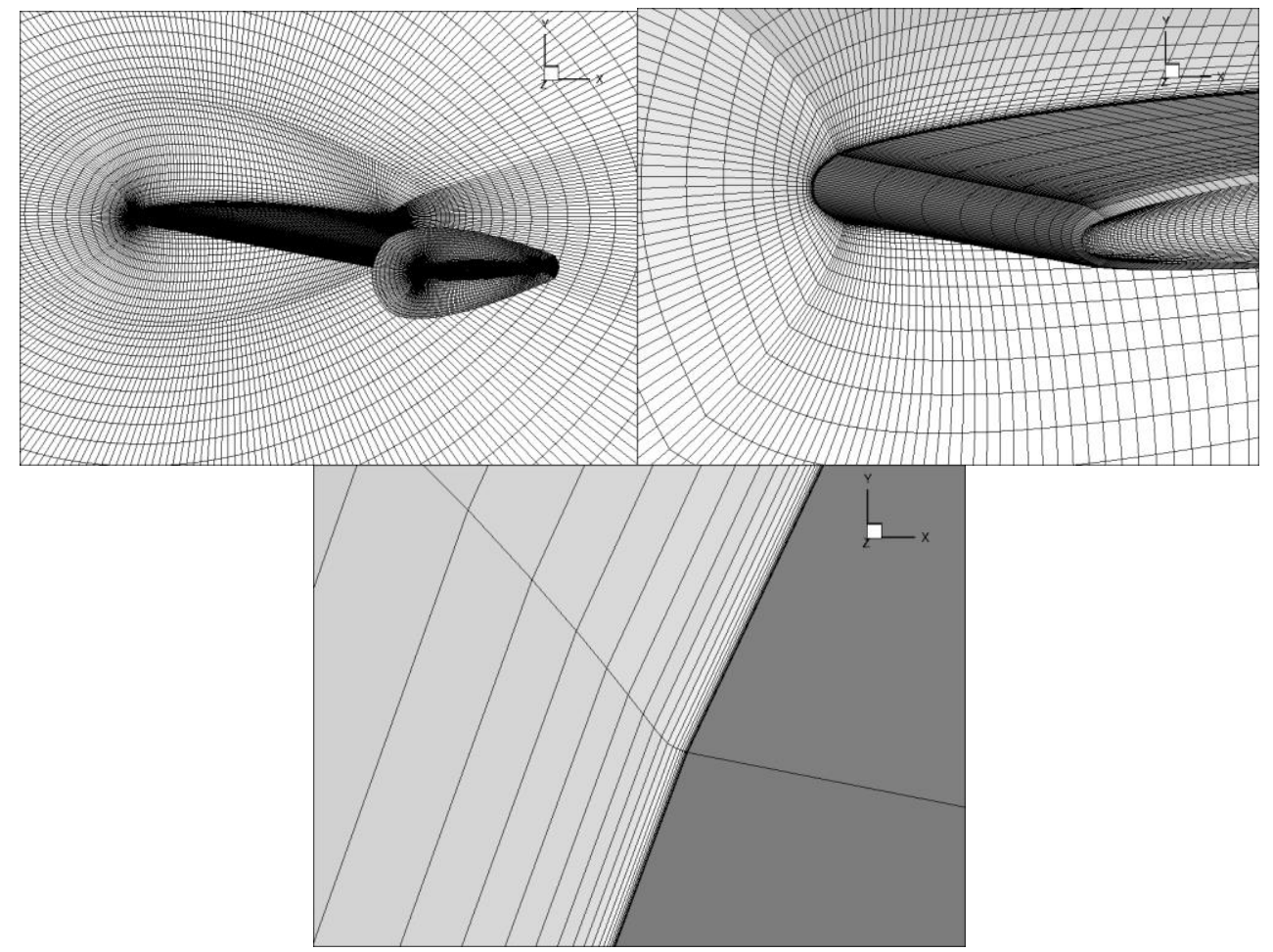

Fig. 5 Orthogonality/stretching check close to wall of the generated grid for iced surface (NSGRID3D). 


\section{References}

[1] Vos J., Rizzi A., Darracq D. and Hirschel E., "Naviers-Stokes solvers in European aircraft design," Progress in Aerospace Sciences, Vol. 38, 2002, pp. 601, 697.

[2] Vos J., Rizzi A., Corjon A., Chaput E. and Soinne E., "Recent Advances in aerodynamics inside the NSMB (Navier-Stokes Multiblock) Consortium," AIAA Journal, 1998.

[3] Vos J., et al., "NSMB 6.04 User Guide, CFS Engineering," Technical Report, Sep. 2011.

[4] Deloze T., Hoarau Y. and Dusek J., "Transition scenario of a sphere freely falling in a vertical tube," Journal of Fluid Mechanics, in press, 2012.

[5] Hoarau Y., Vos J., Deloze T., Charbonnier D. and Rey B., "Automatic Chimera Method for Moving Bodies in NSMB," Overset Grid Symposium, Dayton, Ohio, Oct. 2012.

[6] Tinoco, E., et al., "Summary of the Fourth AIAA CFD Drag Prediction Workshop," 28th AIAA Applied Aerodynamics Conference, Chicago, Illinois, June 2010.

[7] Rumsey C., Long M., Stuever B. and Wayman T., "Summary of the First AIAA CFD High Lift Prediction Workshop," 49th AIAA Aerospace Sciences Meeting, Orlando, Florida, Jan. 2011.

[8] Schuster D. M., Chwalowski P., Heeg J. and Wieseman C. D., "A Summary of Data and Findings from the First Aeroelastic Prediction Workshop," 7th International Conference on Computational Fluid Dynamics (ICCFD7), Big Island, Hawaii, Jul. 2012.

[9] Huang X. Z., Mitchell A. M. and Verhaagen N. G., "Introduction and experimental aspects of the NATO/RTO task group AVT-080: "Study of vortex breakdown over slender wings"," European Congress on Computational Methods in Applied Sciences and Engineering ECCOMAS, Jul. 2004.

[10] Hasanzadeh K., Laurendeau E., and Paraschivoiu I., "Quasi-steady convergence of multi-step Navier-Stokes icing simulations," AIAA Journal of Aircraft, June 2013, DOI: 10.2514/1.C032197.

[11] Hasanzadeh k., Mosahebi A., Laurendeau E., and Paraschivoiu I., "Framework for Multi-Steps Icing Simulation Code CANICE2D-NS," Canadian Aeronautics and Space Institute Conference (CASI), Toronto, Canada, April- May, 2013.

[12] Pena, D., Hoarau, Y., Laurendeau E., "Parallel computing of icing on threedimensional airfoils," 11th World Congress on Computational Mechanics (WCCM XI), 5th European Conference on Computational Mechanics (ECCM V), 6th European Conference on Computational Fluid Dynamics (ECFD VI), July 20 - 25, 2014, Barcelona, Spain.

[13] Hasanzadeh, K., Laurendeau, E., Paraschivoiu, I., "Adaptive curvature control grid generation algorithms for complex glaze ice shapes RANS simulations" AIAA (SciTech 2015), 5-9 January, Kissimmee, FL, USA.

[14] Hasanzadeh K., Mosahebi A., Laurendeau E., and Paraschivoiu I., "Validation and Verification of Multi-Steps Icing Calculation Using CANICE2D-NS Code," 31st AIAA Applied Aerodynamics Conference, San Diego, California, USA, June 2013. 
[15] Hasanzadeh K., Laurendeau E., and Paraschivoiu I., "Adaptive curvature control grid generation algorithms for complex glaze ice shapes RANS simulations," AIAA Journal, Nov. 2014, manuscript ID: 2014-11-J054076.

[16] Hasanzadeh, K., Laurendeau, E., "Validation and User Manual of CANICE2DNS" Technical Report, Bombardier Co., Oct. 2014.

[17] Levesque, A.T., Pigeon , P., Deloze, T., Laurendeau, E., "An overset grid 2D/Infinite swept wing URANS solver using Recursive Cartesian Virtual Grid method" AIAA (SciTech 2015), 5-9 January, Kissimmee, FL, USA.

[18] Bourgault-Côté, S., Laurendeau, E., "Two-Dimensional/Infinite Swept Wing Ice Accretion Model” AIAA (SciTech 2015), 5-9 January, Kissimmee, FL, USA.

[19] Pigeon A., Levesque A. T., and Laurendeau E., "Two-Dimensional Navier-Stokes Flow Solver Developed at Ecole Polytechnique de Montreal," CFD Society of Canada, 22nd annual conference, CFDSC, 2014.

[20] Papadakis, M., Yeong, H.W., Wong, S.C., Vargas, M., Potapczuk, M., "Experimental Investigation of Ice Accretion Effects on a Swept Wing," Technical Report, NASA, DOT/FAA/AR-05/39, Aug 2005. 